\title{
CINE-ANGIOGRAPHY OF THE CORONARY CIRCULATION IN LIVING DOGS
}

\author{
BY \\ GRAEME SLOMAN* AND KEITH JEFFERSON \\ From St. George's Hospital \\ Received April 14, 1959
}

The object of the investigation was to find the most safe and efficient method of coronary angiography in animals, with a view to applying it to human subjects. Grossman (1945) was one of the first to describe radiological investigation of the coronary arteries in live dogs. He injected between $100-150 \mathrm{ml}$. of 70 per cent diodrast in divided doses into the thoracic aorta of 12 dogs, visualization of the coronary arteries was successful in five dogs but four of them died.

Other workers have studied techniques for demonstrating the coronary circulation. Garamella, George, and Hay (1957) inserted a polyethylene catheter via the right carotid artery into the base of the aorta, and injected opaque medium to assess the effects of experimental coronary artery occlusion. Dotter and Frische (1958) used a double-lumen balloon catheter to inject contrast medium into the ascending aorta, proximal to occlusion of the aortic arch by a balloon: by this method, they were able to reduce the volume of contrast medium, and improved visualization of the coronary circulation by inducing cardiac arrest with acetylcholine just prior to the injection. Hughes et al. (1956) and Miller et al. (1957a, 1957b) injected contrast medium into the proximal aorta and studied the coronary circulation in normal dogs and after various surgical procedures. Arnulf (1958) and Arnulf and Chacornac (1958) induced cardiac arrest with acetylcholine and obtained successful coronary angiograms in animals and in men.

\section{MATERIAL AND ApPARATUS}

Twenty unselected mongrel dogs were studied. Their weights ranged from $8 \cdot 2 \mathrm{~kg}$. to $22 \cdot 6 \mathrm{~kg}$. (average $14.8 \mathrm{~kg}$.). Induction of general anæsthesia was carried out with 2.5 per cent sodium thiopentone. In the earlier experiments, atropine sulphate $0.6 \mathrm{mg}$. was added to the sodium thiopentone, but it was discontinued later since it tended to prevent cardiac arrest from the acetylcholine. The omission of atropine from the premedication did not appear to have any adverse effect.

The animals were intubated and respiration was controlled using an intermittent positive pressure respirator (Beaver Mk II). Anæsthesia was maintained with nitrous oxide and oxygen and small additional doses of sodium thiopentone and pethidine. The level of anæsthesia was kept as light as possible and great care was taken to ensure that the animals were fully oxygenated at all times.

The right common carotid artery was exposed with the dog turned 15 degrees toward the right oblique position. Tapes were placed around the artery and a longitudinal incision was made through which the cardiac catheter was passed into the ascending aorta under X-ray control. The electrocardiogram and, in some cases, the electroencephalogram were continuously observed on a cathode ray tube. The central aortic pressure was monitored using a second catheter passed via the left femoral

\footnotetext{
* Leverhulme Research Fellow, Royal College of Physicians, London. Present address: Cardiac Department, Royal Melbourne Hospital, Victoria, Australia.
} 
artery into the thoracic aorta. Recordings of these events were made at intervals and during each injection. Urografin 76 per cent and hypaque, 85 per cent and 90 per cent, were injected with a simple compressed air mechanical injector.* Cine-angiography was performed with a $35 \mathrm{~mm}$. Arriflex camera mounted on a standard 5 inch Philips image intensifier. A monocular viewer enabled the radiologist to see through the shutter of the camera during filming. This allowed an immediate assessment of the quality of each coronary angiogram. Exposure was controlled by a millivolt meter connected to a photo-electric cell in the image intensifier. Fine grain film (Ilford FP3) was used for all angiograms. At a camera speed of 32 frames/second, average radiographic factors were $10 \mathrm{~mA}$ at $70 \mathrm{kV}$. The $35 \mathrm{~mm}$. film was processed commercially $\dagger$ using a high contrast rapid developer. A $16 \mathrm{~mm}$. copy was used for analysis and the $35 \mathrm{~mm}$. film preserved as the master copy.

\section{Present Investigation}

The type of catheter used for injection was important. The earliest angiograms were performed using a standard Cournand cardiac catheter. Sufficiently rapid injection of the opaque medium could not be obtained due to the relatively small internal bore of the catheter: the jet from the single end-hole often forced opaque medium through the open aortic valves during left ventricular systole, and this caused loss of medium from the aorta and resulted in poor filling of the coronary arteries. Through a Lehman wide bore catheter (7F) with four side holes placed spirally up to 2 $\mathrm{cm}$. from the open end-hole, it was found that contrast medium could be injected more rapidly and less reflux occurred into the left ventricle. A Lehman wide bore catheter with the end blocked and multiple side holes was then tried. Fourteen dogs were studied and no reflux occurred from the aorta to the left ventricle. It appeared, therefore, that elimination of the end jet by blocking the catheter tip was essential.

A number of injections during sinus rhythm and cardiac arrest were made with a double lumen balloon catheter as described by Dotter and Frische (1958), the balloon being inflated with oxygen to occlude the ascending aorta, prior to the injection of contrast medium. Fair filling of the coronary arteries was obtained with a smaller dose of contrast medium, but technical difficulties were encountered in positioning the catheter and in occluding the aorta. We therefore considered this catheter unsuitable in our hands for application to human investigations.

The effect of the position of the catheter was studied. With the heart in sinus rhythm, good filling of the coronary arteries was consistently obtained if the tip of the catheter was about $2 \mathrm{~cm}$. above the aortic valve. If the tip was lower, it rested in an aortic sinus and only the near-by coronary artery was adequately filled. If the tip was placed more than about $2 \mathrm{~cm}$. above the valve, the medium failed to enter the coronary arteries and was lost in the aorta. With cardiac arrest, the position of the catheter was not critical. Equally good filling was obtained with the tip just above the aortic valves, in the aortic arch, or in the descending thoracic aorta.

Injection of contrast medium into the left ventricle was also tried. Eight injections in four dogs were carried out with the modified Lehman catheter passed through the aortic valve into the left ventricle. Doses of medium were similar to those employed in the aortic injections. Good left ventricular filling was obtained, but this obscured at least one major branch of a coronary artery (Fig. 1). When arrest was induced with acetylcholine, prior to left ventricular injection, much of the contrast medium was lost through the mitral valve. When sinus rhythm returned after 5 to 10 seconds, the medium was so diluted with blood that no coronary opacification was obtained.

\section{TECHNIQUE OF INJECTION}

A standard dose of $1 \mathrm{ml}$. of contrast medium per $\mathrm{kg}$. of body weight was used. The lower viscosity, at body temperature, of urografin 76 per cent made it more suitable than hypaque 90 per

* Manufactured by Talley Anæsthetic Equipment Ltd., 37a New Cavendish Street, London, W.1.

† George Humphries \& Company, Ltd., 71 Whitfield Street, London, W.1. 
cent for rapid injection. Since the contrast was about the same with either medium, urografin 76 per cent was preferred. Hypaque 85 per cent was available towards the end of the study and its viscosity and contrast were similar to urografin 76 per cent. No arrhythmias or hypersensitivity reactions occurred as a direct result of the injection of opaque media into the aorta.

Rapid injection of the medium was found to be very important. Good filling of the coronary circulation was obtained only when the injection was completed in one second or less. The pressure in the ascending aorta just proximal to the site of injection was measured (Fig. 2). In sinus rhythm, this was found to rise approximately $20 / 15 \mathrm{~mm}$. Hg. during the injection (Fig. 3). When asystole was induced and maintained during the injection phase with acetylcholine, the mean pressure rose about $10 \mathrm{~mm}$. $\mathrm{Hg}$. The rapid injection therefore produced a pressure gradient favouring a flow of contrast medium into the coronary circulation.

Richards and Thal (1958) found it important to inject the contrast medium rapidly towards the end of systole and in early diastole, employing an electronically timed injector. They obtained excellent coronary angiograms in men and we are now investigating this technique.

\section{RESULTS}

With the dogs' hearts beating at about 140 a minute, it was apparent from the early cine films that the contrast medium was being rapidly dissipated down the thoracic aorta by left ventricular ejection. An attempt was made to reduce the left ventricular output by using the Valsalva manœuvre prior to the injection of contrast medium. The Beaver respirator was adjusted to give a positive intra-thoracic pressure of $25 \mathrm{~cm}$. of water. The intra-thoracic pressure was later increased to 


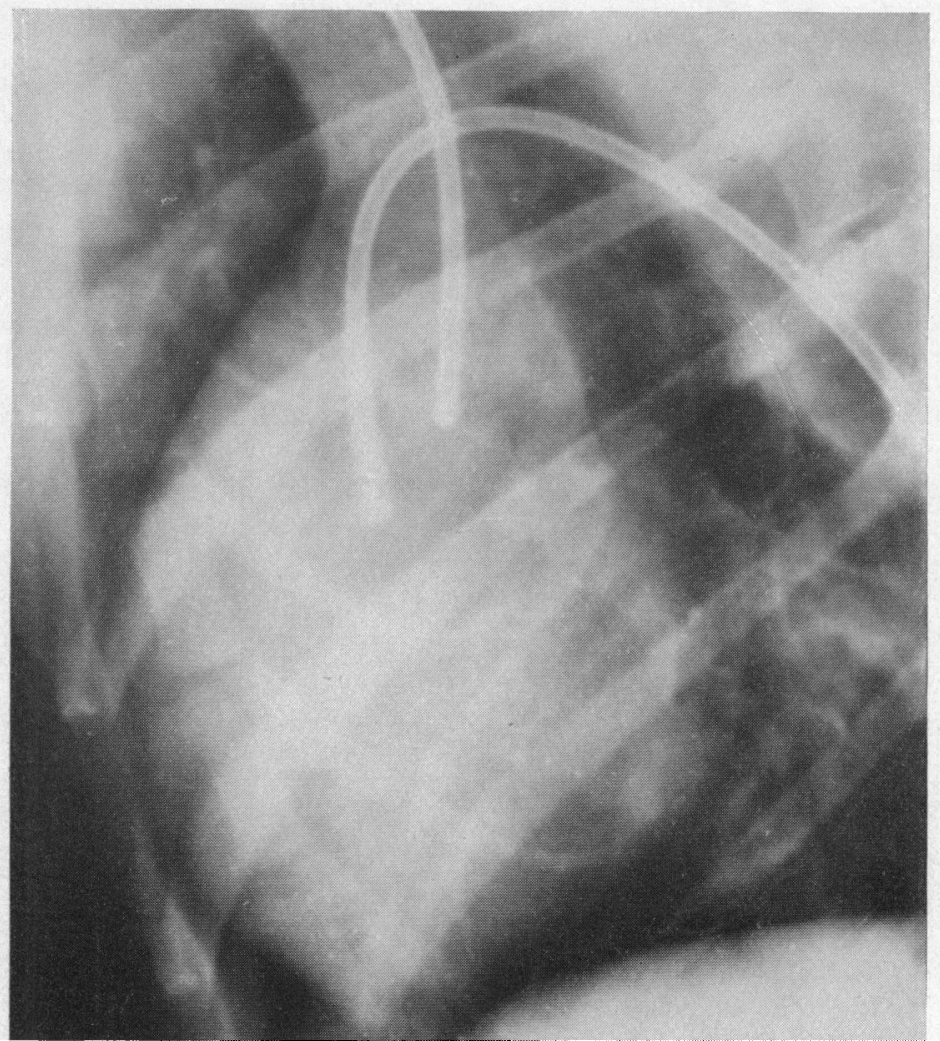

FIG. 2.-Dog in left anterior oblique position. Radiograph showing the position of the two catheters in the ascending aorta. Injection of medium was performed through the upper catheter and the pressure was measured through the lower catheter.

$40 \mathrm{~mm}$. Hg. by compressing an anæsthetic breathing bag connected to the endo-tracheal tube (Fig. 4). These procedures were tried in five dogs and improved the coronary visualization but some contrast medium was still being lost down the aorta (Fig. 5).

Prostigmine was used in doses up to $2 \mathrm{mg}$. to induce bradycardia in order to increase the diastolic filling of the coronary circulation. Atropine sulphate was found to be essential to prevent the undesirable side effects of bronchospasm, defæcation, and micturition, but the heart rate was not then slow enough to improve the coronary artery filling. The short-acting drug edrophonium chloride (tensilon) was also tried in doses up to $20 \mathrm{mg}$., without atropine, but the reduction in pulse rate did not exceed 10 per cent and was without significant effect on the coronary filling.

Gregg and Sabiston (1956) showed that coronary flow and coronary sinus drainage increased after the induction of asystole by vagal stimulation. We therefore decided to try angiography during cardiac arrest. Freshly prepared acetylcholine (Roche crystalline) was injected into the ascending aorta through the catheter. Although small doses of $0.5 \mathrm{mg}$. would sometimes stop the heart, $5 \mathrm{mg}$. were needed to cause arrest lasting 5 to 15 seconds (Fig. 6). Consistently good coronary angiograms were obtained on 103 occasions during cardiac arrest without complication (Fig. 7). No systemic effects occurred from acetylcholine, probably because it was destroyed in the coronary circulation and aorta by the natural cholinesterase before it reached the peripheral circulation. During ventricular standstill, atrial activity sometimes continued as shown by $P$ waves on the electrocardiogram. Atropine sulphate, $0.6 \mathrm{mg}$. in $5 \mathrm{ml}$. saline, terminated asystole when injected through 


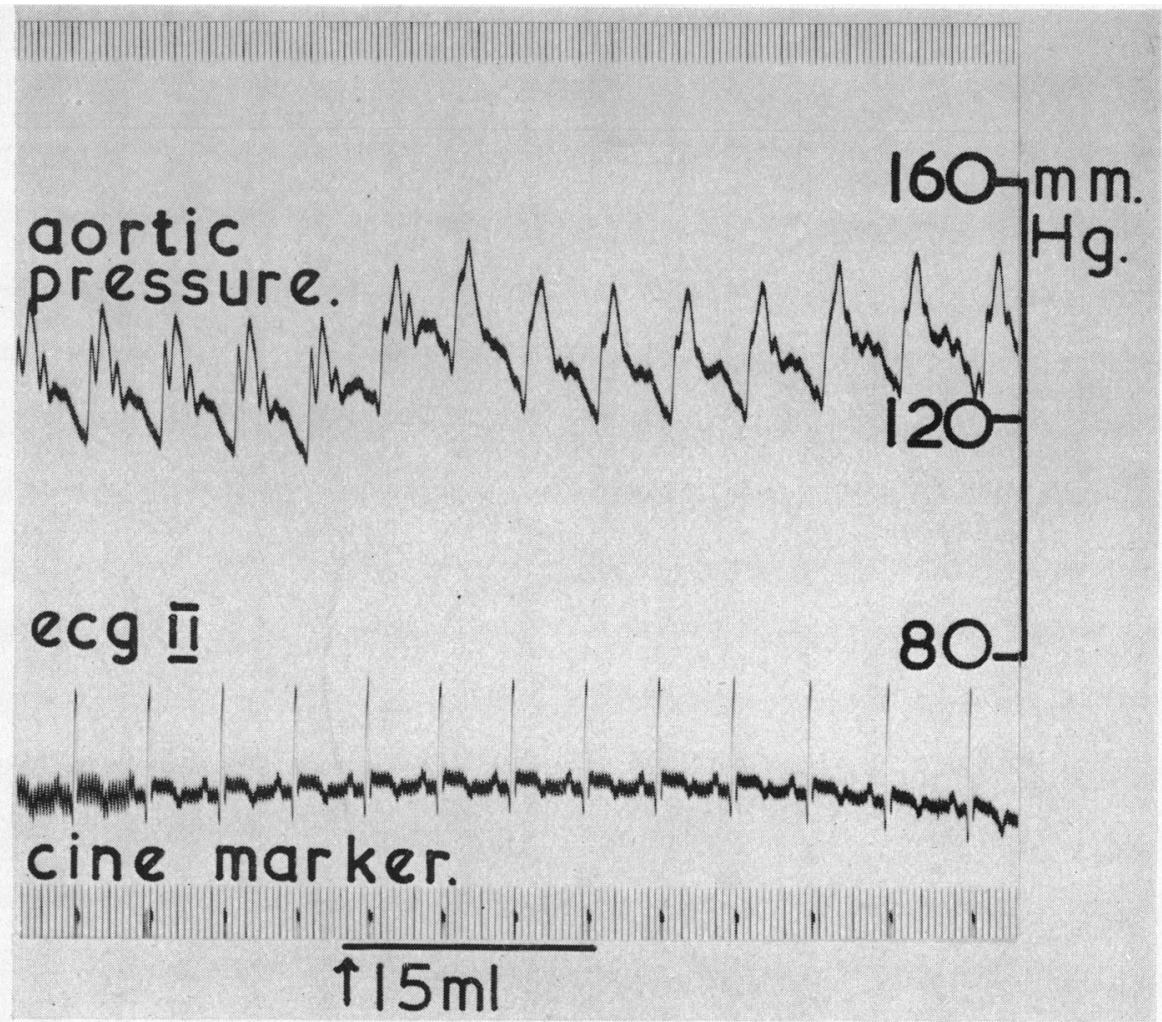

FIG. 3.-Aortic pressure tracing illustrating the rise in aortic pressure during injection of $15 \mathrm{ml}$. of urografin 76 per cent. Sinus rhythm.

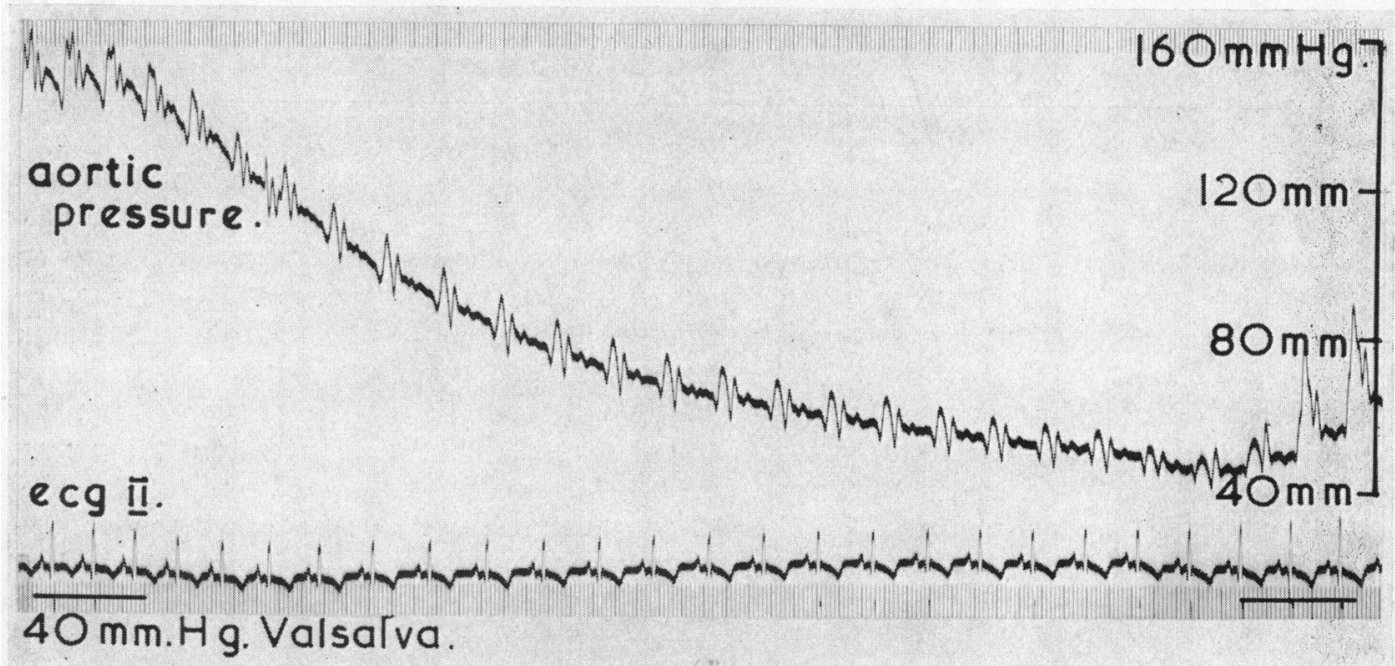

FIG. 4.-Aortic pressure tracing illustrating the fall in aortic pressure during the Valsalva manœuvre. 
the aortic catheter. This effect of atropine was reported by Burn and Walker (1954) using a Starling heart-lung preparation in a dog. They showed that small amounts of atropine, 10 to $20 \mathrm{mg}$., would restore the rate in a heart slowed by acetylcholine. External electric stimulation, using electrodes on the chest wall, was also found to be effective for restarting the heart even after prolonged arrest from $100 \mathrm{mg}$. of acetylcholine and $2 \mathrm{mg}$. prostigmine.

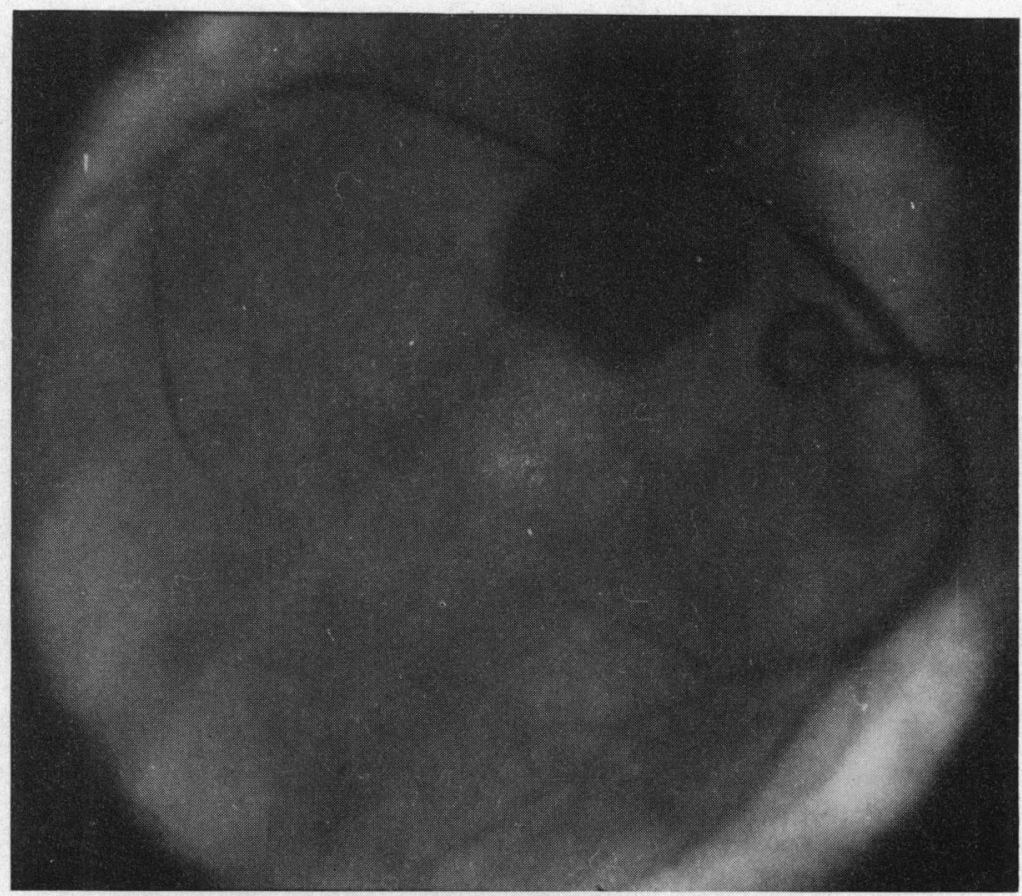

FIG. 5.-Dog in left anterior oblique position. Coronary angiogram performed during a Valsalva manœuvre. Enlargement from contact print of $35 \mathrm{~mm}$. cine-film.

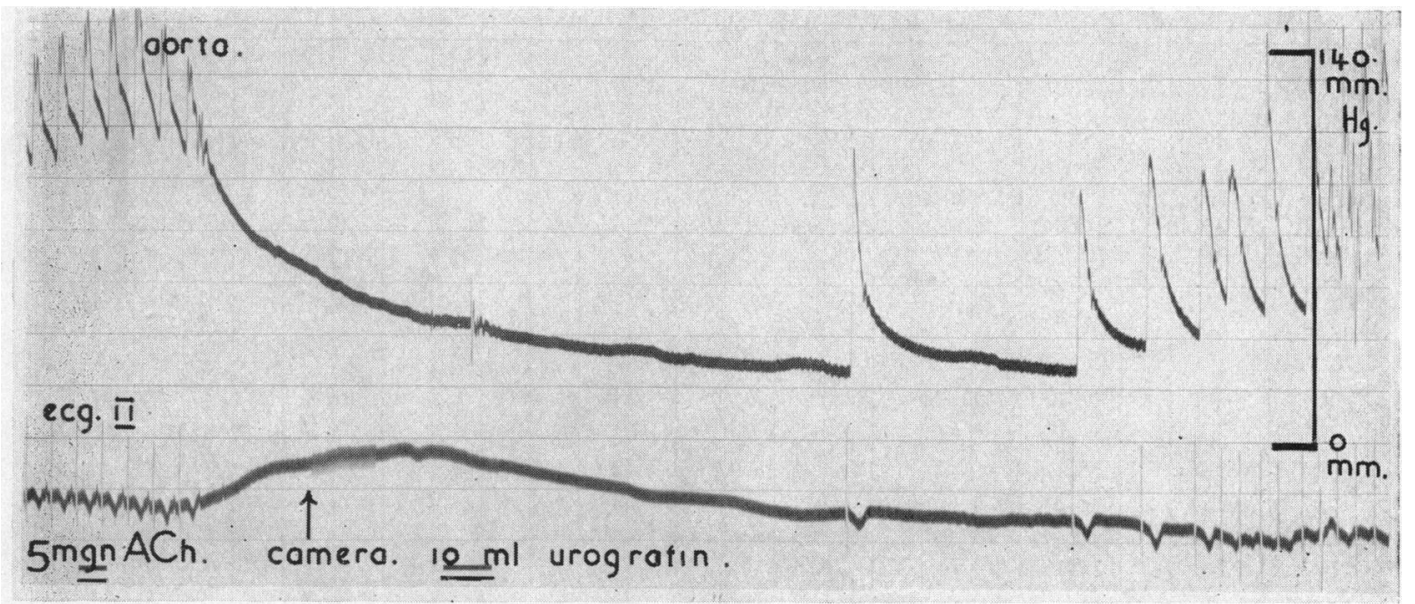

FIG. 6.-Aortic pressure and cardiographic tracings illustrating a period of cardiac arrest induced by $5 \mathrm{mg}$. of acetylcholine. The mean aortic pressure dropped from $120 \mathrm{~mm}$. to $30 \mathrm{~mm}$. $\mathrm{Hg}$. $10 \mathrm{ml}$. of urografin was injected when aortic pressure had fallen to $45 \mathrm{~mm}$. $\mathrm{Hg}$. 


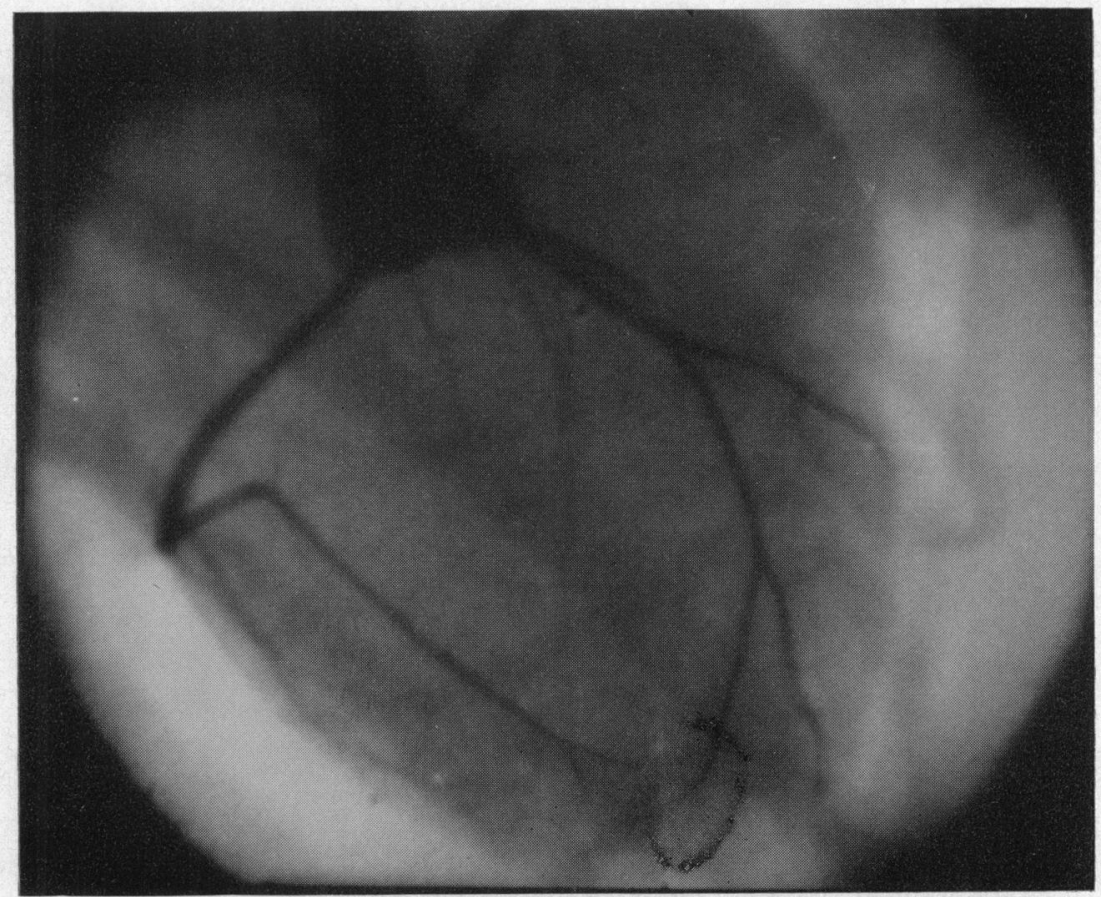

FIG. 7.-Dog in right anterior oblique position. $10 \mathrm{ml}$. of urografin was injected into the aorta during cardiac arrest induced by $5 \mathrm{mg}$. of acetylcholine. Enlargement from contact print of $35 \mathrm{~mm}$. cine-film.

\section{SUMMARY}

Visualization of the coronary circulation in live dogs was achieved by injecting contrast medium into the ascending aorta with the tip of a special catheter $2 \mathrm{~cm}$. above the aortic valve. For good results it was necessary to induce cardiac arrest with acetylcholine. No immediate complications were encountered in 103 injections, either from the contrast medium or from the cardiac arrest. Atropine was confirmed as a safe antagonist to the acetylcholine.

It is thought that this method of coronary angiography may be applicable to the study of the human coronary circulation.

The original idea for this investigation came from Dr. Aubrey Leatham. We thank him for his support throughout the project. We are grateful to Miss Denys Green who was responsible for the radiography and to Mr. J. G. Davies and his staff for their technical assistance.

Dr. D. Howat and Dr. Pamela Ordish developed the method of anæsthesia.

Bayer Products Ltd. supplied hypaque 85 per cent and 90 per cent for clinical trial and from Roche Products Ltd. we obtained edrophonium chloride (tensilon).

\section{REFERENCES}

Arnulf, G. (1958a). Bull. Acad. Nat. Méd. (Paris), 25, 661.

Arnulf, G., and Chacornac, R. (1958h). Lyon Chirurgical (Tome), 54, 212.

Burn, J. H., and Walker, J. M. (1954). J. Physiol., 124, 489.

Dotter, C. T., and Frische, L. H. (1958). Radiology, 71, 502.

Garamella, J. J., George, V. P., and Hay, L. J. (1957). Surg. Gyn. Obst., 105, 89.

Gregg, D. E., and Sabiston, D. C. (1956). Circulation, 13, 916.

Grossman, N. (1945). Amer. J. Roentgenol., 54, 57.

Hughes, C. R., Sartorius, H., and Kolff, W. J. (1956). Cleveland Clin. Quart., 23, 251

Miller, E. W., Hughes, C. R., and Kolff, W. J. (1957). Cleveland Clin. Quart., 24, 41.

, Kolff, W. J., and Hughes, C. R. (1957). Cleveland Clin. Quart., 24, 123.

Richards, L. S., and Thal, A. P. (1958). Surg. Gyn. Obst., 107, 739.

Thal, A. P., Lester, R., Richards, L. S., and Murray, J. (1957). Surg. Gyn. Obst., $105,457$. 